\title{
Responses of temperate reef fishes to alterations in algal structure and species composition
}

\author{
Phillip S. Levin ${ }^{1, *}$, Mark E. Hay \\ Institute of Marine Sciences, University of North Carolina-Chapel Hill, Morehead City, North Carolina 28557, USA
}

\begin{abstract}
Reef habitats in the South Atlantic Bight comprise only a small proportion of the available benthic habitat, but support enormous densities of fishes, invertebrates, and algae. Because these reefs are distant from shore and in deeper waters (usually $>20 \mathrm{~m}$ ), we know very little about the factors affecting the distribution of fishes or the structure of fish assemblages on these reefs. Our goal in this study was to determine how variance in macroalgal structure and species composition on reefs off the coast of North Carolina affects reef fishes. Manipulations of algal density and species composition in artificially created $1.5 \mathrm{~m}^{2}$ plots indicated that: (1) patches with Sargassum filipendula had greater numbers and higher species richness of reef fishes than patches without algae; (2) fishes responded to variability in Sargassum density with high fish abundance in patches with higher algal density, but this response varied among fish species; (3) greater numbers of individuals and species of fish used Sargassum patches compared to patches of 2 other brown algae common in this region (Zonaria and Dictyoptens); (4) fish densitıes were higher in patches with taller algae and greater percent cover of algae. Many of the fishes using experimental patches were small, young-of-the-year individuals. Our results indicate that variability in the structure of seaweed beds on reefs in the South Atlantic Bight can influence the distribution and abundance of reef fishes. Although the algal beds in the South Atlantic Bight are more diminutive and less extensive than kelp beds of cold temperate waters, they may be a critical habitat for juvenile reef fishes in this region, and the algal species dominating the beds will have a large effect on their value as juvenile habitat
\end{abstract}

KEY WORDS: Reef fish - Temperate reef - Habitat structure - Macroalgae $\cdot$ South Atlantic Bight $\cdot$ North Carolina Sargassum Recruitment

\section{INTRODUCTION}

Our current view of marine communities and populations emphasizes vagaries in the delivery of pelagic larvae to local populations and the extent to which adult populations reflect the supply of larvae (Gaines \& Roughgarden 1985, Menge \& Sutherland 1987. Doherty \& Williams 1988, Underwood \& Fairweather 1989). The recent focus by workers on larval supply and recruitment limitation has enhanced our understanding of marine populations; however, it is clear that post-settlement processes are also important in determining the sizes of populations (Forrester 1990, Jones 1991, Hixon \& Beets 1993, Olafsson et al. 1994).

\footnotetext{
- Present address: Texas A\&M University, Department of Marine Biology, 5007 Ave U, Galveston, Texas 77551, USA

E-mail: levinp@tamug2.tamu.edu
}

Moreover, post-settlement processes may be influenced by attributes of the habitat. Hixon \& Beets (1993), for example, demonstrated experimentally that hole size and number influenced the number of resident predators, and this set the upper limit of population size of newly recruited reef fishes in their experimental reefs in the Virgin Islands. Thus, a more pluralistic view of marine populations requires integrating the role of larval supply with the habitat requirements of older, demersal fish (Jones 1991).

Experimental studies of reef fish ecology have traditionally been conducted in coral reef habitats (Sale 1980,1991 ). We therefore know much more about the ecology of tropical reef fishes and how they interact with their habitat than their temperate counterparts (Ebeling \& Hixon 1991). Although temperate reefs themselves lack the tremendous topographic complexity of coral reefs, the extension of macroalgae above 
the reef provides structural complexity that may be utilized by fishes (Ebeling \& Hixon 1991). Algal habitats and their associated invertebrates serve as a source of food (Coyer 1979, Holbrook \& Schmitt 1988, Levin 1994a), and the structural complexity of these habitats provides a refuge from predation. (Ebeling \& Laur 1985, Carr 1991a, Anderson 1993). Recent work on temperate rocky reefs has indicated that macroalgae can influence initial patterns of recruitment (Jones 1984a, Carr 1989, 1991b, 1994a, Levin 1991, 1993) as well as patterns of adult abundance (Choat \& Ayling 1987. Holbrook et al. 1990a, b, Anderson 1994, Carr 1994b). Thus, understanding how fishes respond to variability in seaweed beds may be critical to understanding the dynamics of many populations of fishes on temperate reefs.

Most work on the fishes of temperate reefs has been conducted in kelp-dominated habitats in the Pacific (e.g. Hixon 1980, Larson 1980, Holbrook \& Schmitt 1988, Jones 1988, Holbrook et al. 1990a, b, Anderson 1994. Carr 1994a) and in the Northwest Atlantic (Levin 1991, 1993, 1994b). Although kelps are absent from rocky outcroppings on the continental shelf of the South Atlantic Bight, USA, these reefs support extensive beds of smaller brown algae such as Sargassum filipendula (Fucales) and various genera of Dictyotales. These genera are the understory in some kelp-dominated locales (e.g. Carr 1989, Holbrook et al. 1990a, Schmitt \& Holbrook 1990). Previous work on temperate reefs in other geographic regions suggests that seaweed beds might be important habitats for fishes on reefs of the South Atlantic Bight; however, generalizing from other geographic regions is problematic because of (1) the absence of kelps; (2) the dominance of algal species that occur only as understory species in other regions, but as canopy species in this region $i$ and (3) the marked differences in the fish assemblages.

The goal of our study was to determine experimentally the effects of different algal habitats on the smallscale distribution of reef fishes in the South Atlantic Bight. Specifically we asked these questions: (1) Does the presence of algae influence the distribution of fishes? (2) Does variability in macroalgal density affect the density of fishes? (3) Does reef fish abundance and species richness vary among algal habitats composed of different species? (4) Is differential use of seaweed habitats by fishes the result of qualitative or quantitative differences among algal species?

\section{METHODS}

Study site and organisms. The continental shelf of the South Atlantic Bight is characterized by a complex sequence of rocky outcroppings with relief up to $10 \mathrm{~m}$.
Although sand bottom covers most of the sea floor, about $15 \%$ of the shelf consists of exposed rocky outcroppings that support sponges, hydroids, corals and seaweed beds (Parker et al. 1983). On some reefs macroalgae form extensive beds along the top of the reef, while on other reefs algal coverage is sparse. r. lost of these reefs are distant from shore and in depths $>20 \mathrm{~m}$; consequently, virtually no experimental work has been conducted on the fishes of these reefs. Reefs in this region support a diverse assemblage of tropical and temperate fishes with greater than 114 species representing 43 families (Grimes et al. 1982, Sedberry \& Van Dolah 1984). Tropical groups such as butterflyfishes, damselfishes and tropical labrids (e.g. slippery dicks Halichoeres bivittatus) are frequently found on the same reefs as other more temperate species such as black sea bass Centropristis striata.

Experiments were conducted at a 27 to $31 \mathrm{~m}$ deep reef located $43 \mathrm{~km}$ off the coast of Wilmington, North Carolina, USA $\left(34^{\circ} 10^{\prime} 09^{\prime \prime} \mathrm{N}, 77^{\circ} 23^{\prime} 12^{\prime \prime} \mathrm{W}\right.$; Loran = $27186.0,39157.2)$. The upper portion of the reef consists of flat hard substrate at a depth of $27 \mathrm{~m}$. Near the reef edge, this substrate is generally free of sand and covered by a dense bed of brown algae dominated by Sargassum filipendula. Other brown algae including Dictypoteris membranacea, Zonaria tournefortil, Dictyota spp. and Lobophora variegata are also present and at times common, but less consistently abundant at this site than Sargassum filipendula (seaweeds will hereafter be referred to by their generic name). At other reefs in the region, Zonaria, Lobophora, Dictyopteris or Dictyota can be the dominant seaweeds (Levin \& Hay unpubl. data). At our study site, the algal bed extends from 3 to $>30 \mathrm{~m}$ away from the reef edge depending on season and location along the reef. On one side of the reef edge, the reef drops rapidly to a sand plain at a depth of about $31 \mathrm{~m}$. On its shallower side, the algal dominated portion of the reef merges into a sand-scoured flat that is very sparsely populated by corals, sponges and red and green algae. The relative lack of benthic invertebrates and algae on this portion of the reef contrasts sharply with the biomass of algae that characterizes the reef at the same depth nearer to the reef edge.

Expt 1: Does the presence of algae influence the distribution of fishes? To test the effect of macroalgae on the distribution of fishes, we performed an experiment in which we created $1.5 \mathrm{~m}^{2}$ patches of algae on otherwise barren substratum adjacent to the reef. Algal patches were constructed by attaching natural densities of Sargassum (21 plants $\mathrm{m}^{-2}$, equivalent to 32 per patch) to four $1 \mathrm{~m}$ long ropes fastened with nylon tie wraps to two $1.5 \mathrm{~m}$ pieces of rebar $(0.90 \mathrm{~cm}$ diameter metal rod) that were separated by $1 \mathrm{~m}$ and parallel to each other. We selected Sargassum because it was the 
dominant large brown alga at our study site. For this experiment and all subsequent experiments, algae were collected from other parts of the reef and then attached in situ to rebar frames. Dry mass of Sargassum averaged ca $80(\mathrm{SE}=5.2) \mathrm{g} \mathrm{m}^{-2}$, while the dry mass of other common brown seaweeds such as Dictyopteris and Zonaria was much lower [dry mass of 26.3 $(\mathrm{SE}=6.0)$ and $9(\mathrm{SE}=3.3) \mathrm{g} \mathrm{m}^{-2}$, respectively]. Two replicates of each treatment were arranged in blocks. Replicates within blocks were separated from each other by $>2 \mathrm{~m}$, and blocks were separated from each other by 7 to $8 \mathrm{~m}$. The entire experimental array was positioned $15 \mathrm{~m}$ from the reef edge. On 25 May 1993, 8 Sargassum plots with 32 plants plot $^{-1}$ and 8 control plots, consisting of only rope and rebar, were constructed. Fifteen days later we compared densities of fishes inhabiting Sargassum versus control plots.

Fishes were sampled by enveloping plots with an enclosure constructed of a square rebar frame $\left(3 \mathrm{~m}^{2}\right)$ and plastic walls that were tied together at the top. The anesthetic quinaldine was injected under the plastic and all fishes were collected with dip nets and later identified and measured (standard length) in the lab. This method appeared to sample substrate-associated fishes adequately in that they generally retreated to the substratum when a diver approached. However. this method did not adequately assess densities of more mobile species such as grunts because they simply left the experimental patches as divers carrying the net enclosures approached. Paired $t$-tests were used to test for differences in the mean number of each fish species between treatments. Prior to analyses Bartlett's test was used to test for homogeneity of variances, and in all cases Bartlett's tests indicated that variances were not heterogeneous ( $\mathrm{p}>0.05)$. In addition, we used Fisher's exacts tests to examine differences in frequency of occurrence of fish between Sargassum-addition and control plots.

Expt 2: Does variability in macroalgal density affect the density of fishes? In this experiment we extended Expt 1 and examined whether fishes responded to variability in seaweed density. To do this we used an approach similar to that described for Expt 1. Replicate $1.5 \mathrm{~m}^{2}$ plots were established on 8 July 1993 as described above. On the rebar-rope bases we attached either $4,8,16$ or 32 Sargassum plants plot ${ }^{-1}$. We employed a randomized blocked design such that all treatment levels were represented in each of 6 blocks.

Densities of fishes using algal patches were estimated 17 d later by visually censusing each replicate completely. Censuses followed procedures developed by Sale \& Douglas (1981). A diver approached a patch and at a distance of $2 \mathrm{~m}$ slowly circled the patch while recording the number of active species hovering within $1 \mathrm{~m}$ of the patch. The diver then moved closer to the patch and enumerated demersal species. Finally, the algae themselves were searched. Lengths of fishes were not explicitly examined; however, most fishes censused were either older juveniles (>50 mm TL, total length) or adults. Visibility at this site was good (>15 m), and fishes were easily observed and counted using this method. A blocked 1-way analysis of variance was used to test for differences in the mean number of fishes occupying patches of different densities. Bartlett's test for homogeneity of variances indicated that in all cases variances were homogeneous ( $p>$ 0.05). In addition, we examined differences in species richness among patches with different plant densities using 1-way ANOVA. While patches with greater density are expected to have higher species richness (Hurlburt 1971), we examined species richness without any correction for the density of fishes because we were interested in the number of species present on our algal patches regardless of density. Thus, our measure of species richness has a density bias but does suggest which patches have the greater potential for interspecific interactions.

Expt 3: Do algal species differ in their influence on local density and species richness of fishes? While Sargassum was the dominant canopy-forming alga at our study site, 2 other brown algae, Dictyopteris and Zonaria, were also common at this site, and dominate at some other reefs (Levin \& Hay unpubl. data). Consequently, we asked if fish abundance and species richness varied among habitats composed of different algal species. On 21 July 1993, we created replicate $1.5 \mathrm{~m}^{2}$ plots as before but with 16 plants each of either Sargassum, Dictyopteris or Zonaria. Nine Sargassum patches, 6 Dictyopteris patches and 6 Zonaria patches were assigned haphazardly to plots throughout the experimental array. These patches were constructed by removing algae used in Expt 2 from the plots and adding the appropriate algal species in situ. An unbalanced design was adopted for this experiment because limited bottom time prevented us from creating additional Dictyopteris or Zonaria plots. Patches were censused visually on 25 August 1993 using the methodology described above. Lengths of fishes were not explicitly examined; however, most fishes censused were either older juveniles (>50 mm TL) or adults. A 1 -way ANOVA was used to test for differences in fish abundance and species richness among treatments.

Expt 4: Is differential use of seaweed habitats by fishes the result of qualitative or quantitative differences among algal species? The results of Expt 3 indicated that fish abundance was higher in Sargassum patches than in patches composed of Dictyopteris or Zonaria. Thus, we conducted an experiment to determine if the differential use of seaweed habitats is the result of some qualitative difference among the algae 
(e.g. chemistry), or the result of quantitative differences, such as mean height or biomass, among our treatments. Replicate $1.5 \mathrm{~m}^{2}$ plots ( $\mathrm{n}=7$ for each treatment) were created on 26 August 1993 with the following 4 treatments: (1) 'tall': 16 unmanipulated Sargassum plants; (2) 'medium': 16 Sargassum plants from which an average of about $9 \mathrm{~cm}$ was removed from the bottom of each plant; (3) 'short'. 16 Sargassum plants that were the same height as Zonaria plants (an average of about $26 \mathrm{~cm}$ was removed from the bottom of each Sargassum plant); (4) 'Zonaria': 16 unmanipulated Zonaria plants. The height of each treatment was characterized by haphazardly selecting 3 plants in each plot and measuring them in situ. The percentage cover of algae of each treatment was also determined by centering a $1 \mathrm{~m}^{2}$ quadrat with a grid of monofilament line forming 45 points over the plot and quantifying presence or absence of algae at each point. Fish densities were estimated visually on 7 September 1993 using the same methodology as Expts 2 and 3. Lengths of fishes were not explicitly examined; however, most fishes censused were either older juveniles (>50 mm TL) or adults. One-way ANOVA and post hoc Tukey's HSD tests were used to assess differences in fish abundances among the treatments. In all cases Bartlett's test indicated that variances were homogeneous.

We selected Sargassum and Zonaria for the above experiment because they co-occur at our site, are the dominant species in this region and have a similar relationship between weight and height (see 'Results')i consequently, when we shortened Sargassum plants we produced plants that were similar in both height and weight to Zonaria. Therefore, differences between Sargassum treatments and Zonaria would indicate that some qualitative differences between species result in differential habitat use by fishes. Differences among Sargassum treatments, but not between the short Sar- gassum and Zonaria treatment, would indicate that quantitative differences between these seaweeds result in different patterns of habitat use by fishes.

\section{RESULTS}

\section{Expt 1: Does the presence of algae influence the distribution of fishes?}

Reef fish abundance clearly increased in response to the addition of seaweeds to the sand-plain habitat (Table 1). Plots with 32 Sargassum plants attracted about 5 times as many total fishes as control plots made of only rope and rebar ( $t$-test, $p<0.01$ ). Every fish family was more abundant or more frequent on Sargassum plots than on control plots with these differences being significant for Blenniidae (primarily seaweed blennies Parablennius marmorensus) and Serranidae (primarily black sea bass Centropristis striata) (Table 1). Filefish (Balistids), blennies, and spottail pinfish (Sparidae) occurred only in plots with Sargassum (Table 1). The density of labridae (primarily slippery dicks Halichoeres bivittatus) doubled in response to Sargassum addition, but this increase was not statistically significant (Table 1).

From our experimental plots, we captured a total of 86 fishes representing 16 species. Species richness on algal patches averaged $4.0(\mathrm{SE}=0.72)$ species plot $^{-1}$, and was significantly greater than the 1.4 (SE $=0.245$ ) species plot $^{-1}$ captured on control plots ( $t$-test, $p=$ $0.006)$

More than $60 \%$ of the fishes collected in this experiment were less than $20 \mathrm{~mm}$ in total length, indicating that most of these fishes (other than blennies) were juveniles. The average total length of fish we collected was $42.8 \mathrm{~mm}$ (SE $=6.0)$.
Table 1. Mean (SE in parentheses) density of fishes, grouped by families, for $1.5 \mathrm{~m}^{2}$ experimental plots that contained 32 Sargassum plants attached to a rope and rebar frame and plots with only rope and rebar (control). $t$-tests were used to detect differences between means. In addition, differences in frequency of occurrence were analyzed with Fisher's Exact Test. -: tests were not performed because means were 0 or frequencies were $100 \%$

\begin{tabular}{|lcccc|}
\hline Fish family & $\begin{array}{c}\text { Sargassum } \\
\text { addition plots }\end{array}$ & Control plots & $\begin{array}{c}t \text {-test } \\
\text { probability }\end{array}$ & $\begin{array}{c}\text { Fisher's Exact Test } \\
\text { probability }\end{array}$ \\
\hline Balistid & $1.3(0.53)$ & $0(0)$ & - & 0.075 \\
Blenniid & $2.3(0.84)$ & $0(0)$ & - & 0.005 \\
Labrid & $2.1(0.69)$ & $1.0(0.63)$ & 0.291 & 0.217 \\
Serranid & $2.4(0.63)$ & $0.6(0.4)$ & 0.036 & 0.035 \\
Sparid & $0.88(0.40)$ & $0(0)$ & - & 0.105 \\
Other & $0.63(0.18)$ & $0.4(0.23)$ & 0.471 & - \\
Total & $9.5(2.1)$ & $2.0(0.32)$ & 0.01 & - \\
\hline
\end{tabular}

\section{Expt 2: Does variability in macroalgal density affect the density of fishes?}

When we manipulated Sargassum density $\left(4,8,16\right.$, or 32 plants plot $^{-1}$ ) rather than just the presence or absence of plants, total fish density increased with increasing Sargassum density (Fig. 1); however, the relationship between fish density and plant density differed among species. Black seabass, for example, gradually increased in density as Sargassum density increased, but the fish were present in all treatments (Fig. 1). In contrast, spottail pinfish did not occur in the 4 -plant treatment, occurred at very low densities 
in the 8-plant treatment, but were abundant in both the 16-and 32-plant treatments (Fig 1). The response of slippery dicks differed from both of the previous species. Slippery dicks were rare in the 4 -plant treatment but equally abundant in plots with 8,16 , or 32 plants plot ${ }^{-1}$. This suggests that above some threshold density of Sargassum, increasing algal density did not affect the density of slippery dicks.
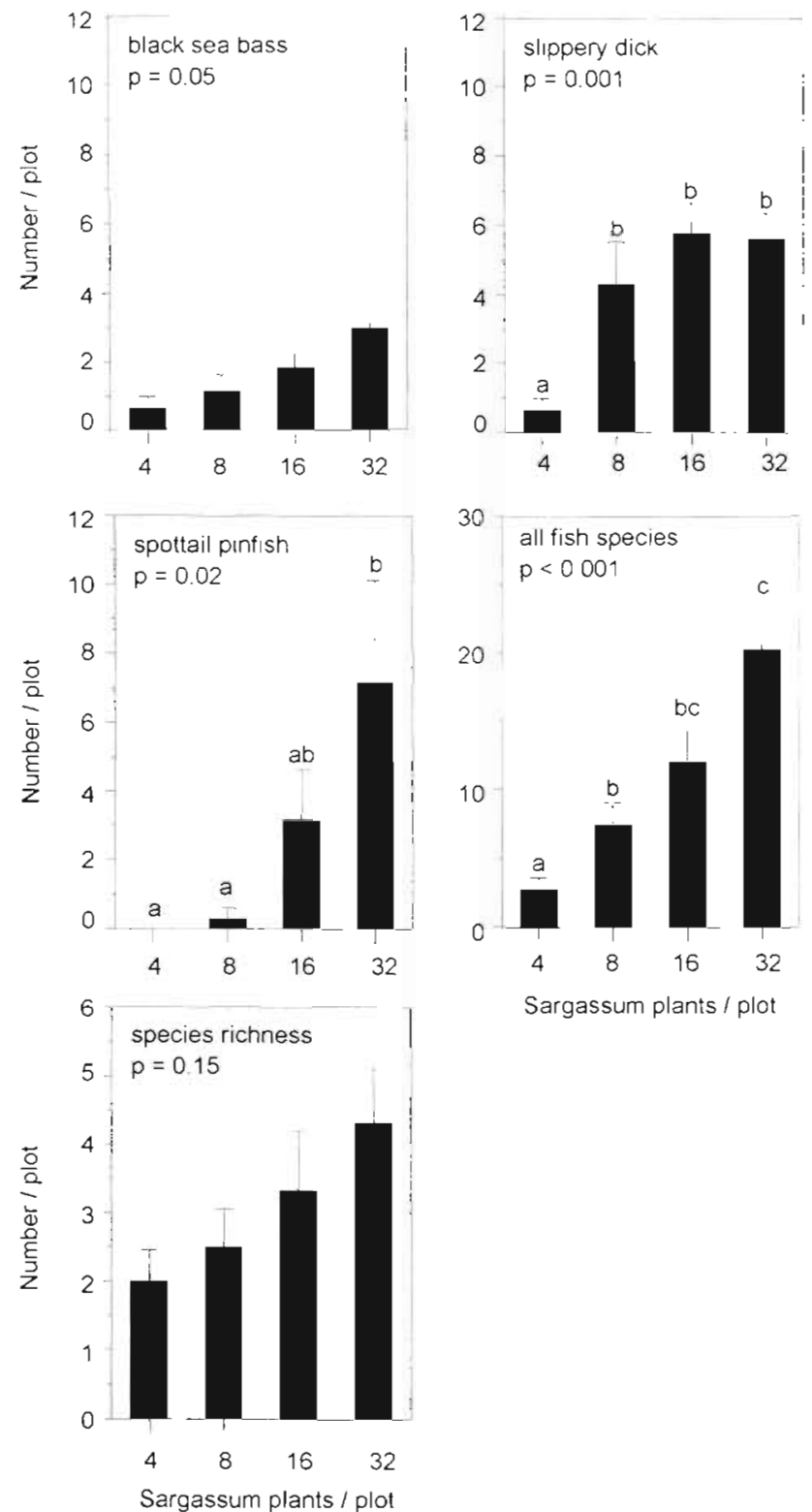

Fig. 1. Mean density of fish or fish species on experimental plots of varying Sargassum density $(N=6)$. p-values are from the overall ANOVA. Letters indicate means that were not significantly different in Tukey's HSD tests. No letters are present for black sea bass since differences could not be identified by Tukey's HSD tests. Error bars are 1 SE. Note that the $y$-axis scales differ among some graphs
When we examined all species combined, there was a clear and significant effect of Sargassum density on fish abundance. Fish densities were more than 7 times greater on 32-plant plots than on 4-plant plots, and nearly 3 times as many fishes occurred on 32-plant plots as on 8-plant plots (Fig. 1). Fish species richness also appeared to increase with increasing Sargassum density, but this trend was not statistically significant (ANOVA, $\mathrm{p}=0.15$; Fig. 1).

\section{Expt 3: Do algal species differ in their influence on local density and species richness of fishes?}

When we held plant density constant at 16 plants plot $^{-1}$, but varied the species of brown seaweed used to create the seaweed patches, fishes strongly preferred plots composed of Sargassum to those composed of either Dictyopteris or Zonaria (Fig. 2). Total fish density on Sargassum plots was more than 8 times that

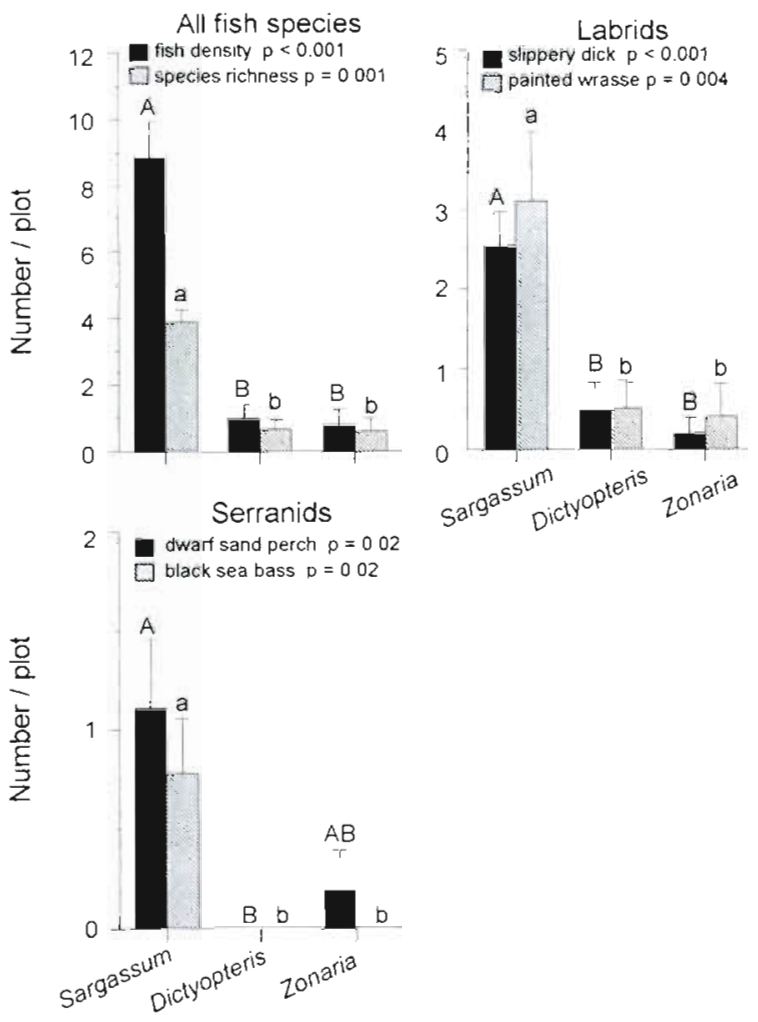

Fig. 2. Mean density of fish or fish species on plots composed of 16 plants of either Sargassum $(N=9)$, Dictyopteris $(N=6)$, or Zonaria $(N=6)$. p-values are from the ANOVA. Letters indicate means that were not significantly different by Tukey's HSD test. Upper case letters refer to means designated by solid bars; lower case letters refer to means designated by hatched bars. Error bars are $1 \mathrm{SE}$. Note that $y$-axis scales differ among graphs 


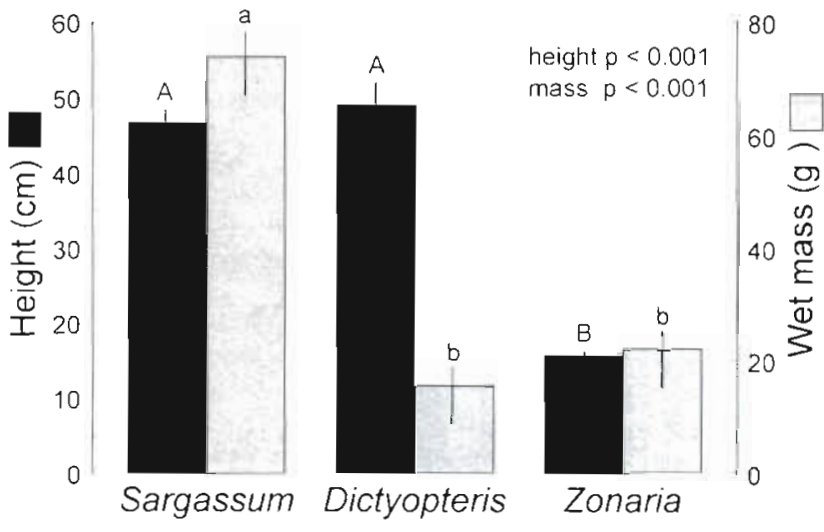

Fig. 3. Mean helght and wet mass of individual Sargassum, Dictyopteris, or Zonaria plants. p-values are from ANOVA. Letters indicate means that were not significantly different by Tukey's HSD test. Upper case letters refer to means designated by black bars while lower case letters refer to means designated by hatched bars. Error bars are $1 \mathrm{SE}$

observed on either Dictyopteris or Zonaria plots (Fig 2; ANOVA, $p<0.001$ ). Four fish species in 2 families comprised $96 \%$ of all the fishes we observed on these plots, and these 4 species showed patterns similar to those

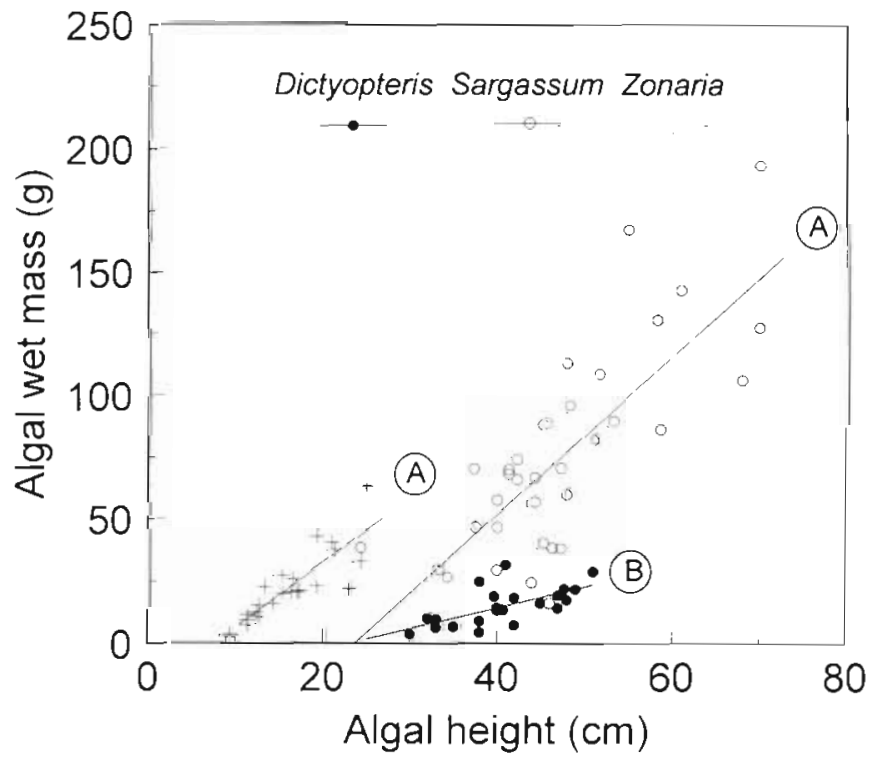

Fig. 4. Linear regression indicated that there was a significant relationship between wet mass and height for Dictyopteris $\left(r^{2}=0.42, p<0.001\right)$, Sargassum $\left(r^{2}=0.60, p<0.001\right)$, and Zonaria $\left(\mathrm{r}^{2}=0.79, \mathrm{p}<0.001\right)$. Analysis of covariance indicated that the slopes of the regression lines of mass versus height for Sargassum and for Zonaria do not differ from each other, but both are significantly greater than the slope for Dictyopteris $(F=43.56, p<0.001)$. Letters indicate regression lines that were not significantly different from each other by Tukey's HSD tests noted for total fish densities (Fig. 2). Slippery dicks and painted wrasses (Labridae) were both significantly more abundant in patches of Sargassum than in patches of Dictyopteris or Zonaria. Black seabass and dwarf sandperch (Serranidae) exhibited a similar pattern, with the exception that dwarf sand perch densities did not differ significantly between Sargassum and Zonaria plots $(p=0.09)$ even though densities in Sargassum were more than 5 times higher (Fig 2). Fish species richness was also much higher in Sargassum than in either of the other species' plots (Fig. 3; ANOVA, $p<0.001$ ). The mean number of fish species per plot was 6 times higher in Sargassum patches than in either Dictyopteris or Zonaria.

\section{Expt 4: Is differential use of seaweed habitats by fishes the result of qualitative or quantitative differences among algal species?}

The species of brown algae we used in the above experiment differed from each other in secondary metabolite chemistry (Hay \& Fenical 1988), the height and mass of algae represented by equal densities of plant, and probably numerous other attributes (Fig. 3). Sargassum and Dictyopteris plants averaged nearly $50 \mathrm{~cm}$ in height and were significantly taller than plants of Zonaria which averaged only $16 \mathrm{~cm}$ in height (Fig. 3). Additionally, the average Sargassum plant had a wet mass of $74 \mathrm{~g}$ and weighed significantly more than either Zonaria (22 g) or Dictyopteris (15 g) (Fig. 3). Sargassum and Zonaria plants also produce more biomass for a given height than Dictyopteris (Fig 4). The slopes of regression lines of weight versus height for Sargassum and for Zonaria did not differ from each other, but both were significantly greater than the slope for Dictyopteris (Fig. 4).

In this experiment, we constructed algal habitats made of equal densities of either short, medium, or tall Sargassum, or of unmanipulated Zonaria, which was similar to short Sargassum in height and the percentage cover it produces (Table 2). Additionally, because Sargassum and Zonaria have a similar height-weight relationship (Fig. 4), short Sargassum were similar in biomass to Zonaria. Fishes responded strongly to the taller Sargassum (Fig. 5). Total fish density in the tall Sargassum treatment was a significant 2 times greater than in the medium Sargassum treatment, and a significant 7 times greater than in the Zonaria or short Sargassum treatments (Fig. 5). This pattern was particularly evident in slippery dicks (a labrid), and in serranids (Fig. 5). Slippery dicks were absent from both the short Sargassum and Zonaria treatments and were 7 times more abundant on the tall than on the medium Sargassum plots (Fig 5). Similarly, when slip- 
Table 2. Summary of the mean (SE in parentheses) algal height and algal cover resulting from plant height manipulations in Expt 4. ANOVA indicated significant differences among treatments in both height $(F=33.66 ; \mathrm{p}<0.001)$ and cover $(F=17.07 ; \mathrm{p}<0.001)$. Letters to the left of each mean in the table indicate means that were significantly different $(\alpha \leq$ 0.05 ) in post hoc Tukey's HSD tests

\begin{tabular}{|llc|}
\hline Treatment & $\begin{array}{c}\text { Height }(\mathrm{cm}) \\
\mathrm{N}=18 \text { plants }\end{array}$ & $\begin{array}{c}\text { Percentage cover } \\
\mathrm{N}=7 \text { plots }\end{array}$ \\
\hline 'Tall' Sargassum & A $43.22(2.37)$ & A $46.43(4.73)$ \\
'Medium' Sargassum & B $34.50(3.63)$ & A $38.89(6.31)$ \\
'Short' Sargassum & C $17.27(0.83)$ & B $10.11(1.79)$ \\
Zonaria & C $15.94(1.08)$ & B $19.00(1.24)$ \\
\hline
\end{tabular}

pery dicks were grouped with other labrids, abundances on tall Sargassum were significantly greater on tall versus medium Sargassum treatments, both of which had higher abundances than short Sargassum and Zonaria (Fig. 5). Serranids were also most abundant in tall Sargassum plots, less so in medium Sargassum plots, and occurred at low and similar abundance in both Zonaria and short Sargassum plots (Fig. 5). ANOVA indicated a significant difference in serranid densities among the treatments ( $p=0.048)$, but differences could not be identified in subsequent multiple comparison tests (Tukey's HSD, $p>0.05$ for all comparisons).

Because percentage cover of a patch was related to the mean height of plants in that patch $\left(r^{2}=0.21, p=0.02\right)$, height and percentage cover were partially confounded. In an attempt to distinguish between the effects of height and cover, we performed regression analyses using fish densities as the response variable and either percentage cover or the mean plant height in a patch as the independent variable. Both percentage cover and height explained a significant amount of variation in the total abundance of fishes (Fig. 6), with algal height appearing to explain more variance than percentage cover. Additionally, algal cover and height appeared to differentially affect the abundance of particular fish species. Dwarf sandperch densities were significantly affected by algal height $\left(\mathrm{r}^{2}=0.31, \mathrm{p}<\right.$ $0.01)$, but not cover $\left(r^{2}=0.05, p=0.25\right)$. Slippery dicks also responded more strongly to algal height $\left(\mathrm{r}^{2}=0.61, \mathrm{p}<\right.$ $0.001)$ than to algal cover $\left(\mathrm{r}^{2}=0.31, \mathrm{p}<\right.$ $0.01)$. In contrast to these patterns, young-of-the-year black sea bass $(<50$ $\mathrm{mm} \mathrm{TL}$ ) showed no response to variability in algal height $\left(r^{2}=0.04, p=0.5\right)$, but a weak, yet significant response to algal cover $\left(r^{2}=0.15, p<0.05\right)$.
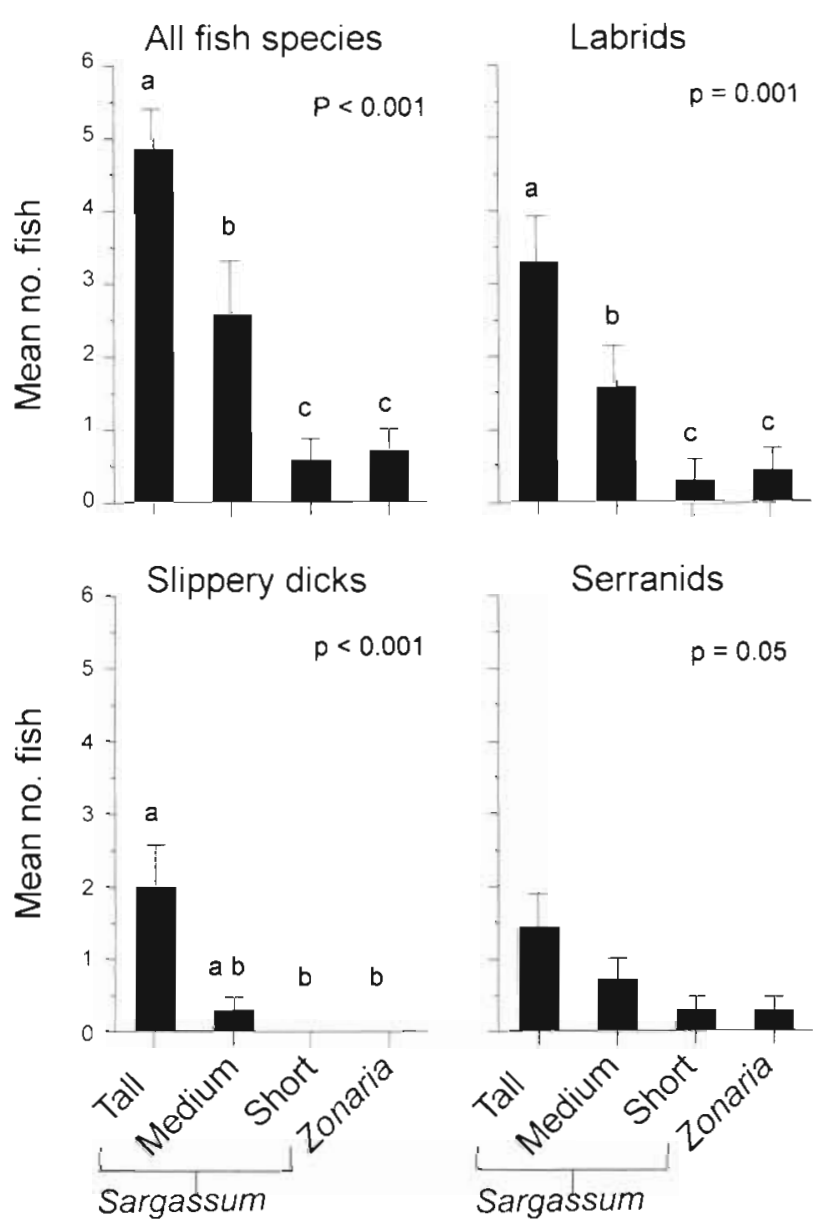

Fig. 5. Mean density of fish on experimental plots composed of 16 tall, medium, or short Sargassum plants, or on 16 Zonaria plants ( $\mathrm{N}=7$; see Table 2 for details of experimental treatments). p-values are from the ANOVA. Letters indicate means that were not significantly different in Tukey's HSD tests. Error bars are $1 \mathrm{SE}$
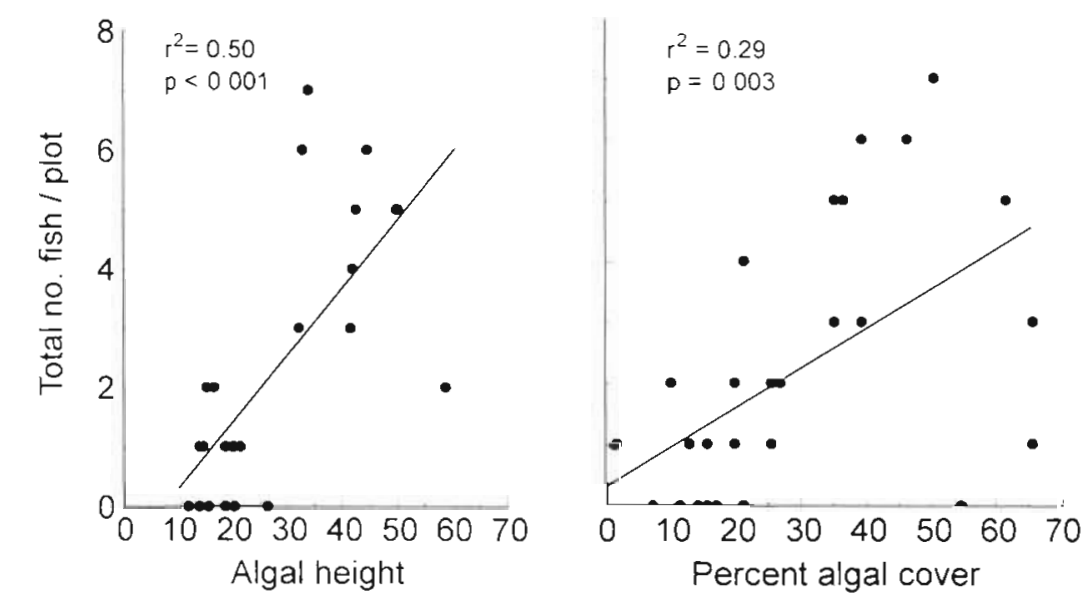

Fig. 6. Relationship between total density of fish (all species combined) and both algal height and percentage algal cover 


\section{DISCUSSION}

Fishes, especially juveniles, in freshwater (Werner \& Gilliam 1984), estuarine (Orth et al. 1984, Sogard 1989) and temperate marine (Holbrook et al. 1990a, b) habitats are frequently associated with submerged vegetation. Previous studies of how temperate reef fishes respond to macroalgae have focused on kelp-dominated communities of New Zealand, California, and New England, USA (Holbrook \& Schmitt 1984, Jones 1984a, b, c, Ebeling \& Laur 1985, Carr 1989, 1991b, $1994 a, b$, DeMartini \& Roberts 1990, Holbrook et al. 1990a, b, Schmitt \& Holbrook 1990, Levin 1991, 1993, 1994a, b, Anderson 1994). In these studies, kelp density and height are often important predictors of reef fish density and recruitment. This may occur, in part, because (1) large kelps such as Macrocystis extend continuously from the benthos to the water surface allowing the kelps to 'collect' recruits that might otherwise pass over the reef; or (2) this large vertical gradient provides the recruiting fish a spatial refuge from predators which tend to be more numerous near the benthos (Coyer 1979, Carr 1994b). As an example of the latter, recently settled kelp bass are most abundant in the upper portions of Macrocystis beds while their older, and cannibalistic, conspecifics are more abundant lower in the canopy (Carr 1994b). Presumably, as kelp bass increase in size, they become less susceptible to predation and migrate down the kelp canopy to the benthos and across the reef. Neither of the 2 processes described above is likely to occur on similar spatial scales in our study because the largest seaweeds in the South Atlantic Bight produce a canopy height of no more than about $0.5 \mathrm{~m}$ (Table 2). These seaweeds, therefore, extend through no more than $2 \%$ of the depth of the water column at our study site.

Although reefs in the South Atlantic Bight lack large kelps, presence and abundance of smaller seaweeds such as Sargassum still strongly influenced fish densities and species richness. Total fish density and species richness increased 5 - and 3 -fold, respectively, when Sargassum was added to an unstructured, sandscoured portion of the reef. Because more than $60 \%$ of the fishes collected during this experiment were less than $20 \mathrm{~mm}$ long, we suspect that most were recent recruits (i.e. young-of-the-year). Sargassum abundance (rather than just presence or absence) also strongly affected fish densities and species richness. Fish densities increased 7 -fold as Sargassum density was increased from 4 to 32 plants plot $^{-1}$.

Fish use of seaweed patches varied tremendously as a function of the algal species comprising the patch. When patches were constructed of equal densities of Sargassum, Dictyopteris, or Zonaria, total fish densities were 8 times higher on Sargassum plots than on plots of the other 2 seaweeds. Differences in fish density between Sargassum and Zonaria plots ultimately disappeared as we made Sargassum increasingly shorter by cutting it into smaller lengths. The finding that short Sargassum did not differ from Zonaria in height, percentage cover or use by fishes suggests that fishes used Sargassum plots more than plots composed of other algae because of the greater height, percentage cover or biomass provided by this species. The stronger association of fish densities with algal height as opposed to percentage cover suggests that some aspect of algal 3dimensionality may be important in determining habitat quality for these fishes. This is also supported by the finding that tall Sargassum was more attractive to fishes than medium Sargassum, and these Sargassum treatments differed in height but not percentage cover.

Although many previous studies have documented strong correlations between kelp abundance and fish abundance, relatively few have assessed how different seaweed species or morphological types affect habitat utilization by fishes. On reefs in California, if the giant kelp Macrocystis is common, small turfs of algae and benthic animals dominate the understory, and foliose species such as Sargassum, Dictyopteris, and Zonaria are rare (Holbrook \& Schmitt 1984, Carr 1989, Holbrook et al 1990a, b, Schmitt \& Holbrook 1990). If Macrocystis is removed, smaller foliose species like Sargassum, Dictyopteris, Zonaria, and other foliose algae can become common (Carr 1989, Holbrook et al. 1990a, Schmitt \& Holbrook 1990). Similarly, in New England, when laminarian kelp is removed, filamentous and foliose species dominate the algal assemblage (Levin 1993). Several studies have noted that small and large fishes respond differently when kelps are removed from these reefs. When Carr (1989) removed Macrocystis from transects within a Macrocystis bed he found that use of areas without kelp declined for large fishes, but increased for smaller fishes that were attracted to the short understory algae, which included Sargassum and several Dictyotaceae (seaweeds that were common in our study) that increased in abundance following Macrocystis removal. In areas where reefs occur as either kelp beds or urchin barrens, small fishes that are dependent on the structure provided by seaweeds generally occur in kelp beds, while larger fishes that are independent of this structure often occur in high abundance over urchin barrens (Choat $\&$ Ayling 1987, Levin 1993). Thus, numerous studies from several geographic localities indicate that small, recently settled fishes depend heavily on algal-generated structure, but can become increasingly independent of such structure as they increase in size (Holbrook \& Schmitt 1984, Jones 1984 a, c, Ebeling \& Laur 1985, Choat \& Ayling 1987, Carr. 1989, Holbrook et al. 1990, Levin 1993). 
Some temperate reef fishes selectively settle in habitats with increased structural complexity (Jones 1984a, Levin 1993), while others settle randomly but experience high mortality in simple habitats and much lower mortality in more complex habitats (Connell \& Jones 1991). These observations, as well as other investigations (Holbrook \& Schmitt 1984, Jones 1984c, Ebeling \& Laur 1985, Carr 1991a, Levin 1994b) suggest that predation may restrict new recruits and juvenile fishes to seaweed dominated areas of temperate reefs, where structural complexity is high. If successful recruitment and survival to early juvenile stages determines adult population size (e.g. Doherty \& Fowler 1994), then variability in algal abundance could result in corresponding variability in fish populations (Anderson 1994, Carr 1994a).

Although there is a considerable literature on the potential importance of larval supply to the population dynamics of marine organisms (Underwood \& Denley 1984, Doherty \& Williams 1988, Roughgarden et al. 1988, Grosberg \& Levitan 1992), recent work has shown or suggested that mortality of newly settled individuals, often as a result of predation, is critical in determining subsequent population size (Shulman \& Ogden 1987, Hixon \& Beets 1993, Levin 1994b), On temperate reefs, seaweeds can be critical components of habitat quality that determine survivorship of juvenile fishes. If these fishes become less dependent on seaweed-generated structure as they mature, then the regional abundance of seaweeds could ultimately affect adult populations that do not use seaweeds at all. As a possible example of this, at our study site, juvenile gag grouper and scamp grouper $(<300 \mathrm{~mm}$ fork length) are found almost exclusively in the seaweed bed and begin using other, seaweed depauperate but structurally complex, portions of the reef only after they exceed the $300 \mathrm{~mm}$ size class (G. McFall \& A. Hulbert, National Undersea Research Center, Wilmington, NC, unpubl. data).

If seaweeds are critical for juveniles but not adults, then the effects of periodic seaweed blooms could persist as strong year-classes of fishes long after the seaweeds are gone. In the South Atlantic Bight, about $85 \%$ of subtidal habitats are composed of sandy substrates that do not support seaweeds or reef fish. However, unusually large storms can remove the sand veneer from reefs and result in large increases in seaweed biomass (Renaud et al. unpubl.). These periodic expansions of algae could result in unusually high rates of fish recruitment. Moreover, for fishes, such as gag grouper, that settle in estuaries and migrate offshore after several months, the increased algal cover may increase available food and decrease mortality as they migrate $>40 \mathrm{~km}$ to the reef habitat that they will occupy as adults. In other types of communities, asso- ciations that protect juveniles during a critical early stage can create pulses of adults long after the protective symbiont is gone. In kelp beds, grazing on kelp sporelings by fishes is significantly reduced if the sporelings grow within patches of filamentous algae. If sporelings can survive this early stage, they rapidly achieve a size where fish grazing is no longer a threat (Harris et al. 1984). Similarly, spiny nurse plants in deserts prevent vertebrate grazers from killing young plants that later may persist in the presence of grazers even if the nurse plant dies (McAuliffe 1986).

From our experiments in North Carolina and from other work conducted in New England (Levin 1991, 1993, 1994b), New Zealand (Jones 1984a, b, 1988), and California (Ebeling \& Laur 1985, Carr 1989, 1991a, b, 1994a, b, DeMartini \& Roberts 1990. Holbrook et al. $1990 \mathrm{a}, \mathrm{b}$ ), it seems clear that seaweeds provide a critical habitat for settlement and early development of many temperate reef fishes. Despite the growing number of studies that document the importance of seaweeds to temperate reef fishes, there are few studies assessing what characteristics of seaweed beds are important to fishes. Understanding how various characteristics of algal beds influence settlement and subsequent retention of settlers on reefs would allow additional tools for the management of reef fisheries. For example, if a target fish population was limited by inadequate habitat for its early life stages, recruitment could be enhanced by (1) augmenting algal beds via the removal of urchins or the management of urchin outbreaks (Jones 1984a, Carpenter 1990); or (2) by the addition of sources of algal spores (Dayton 1973, Paine 1979).

In a recent review, Jones (1988) noted that characteristics of the habitat appeared to have a much greater effect on temperate reef fishes than the fishes have on the habitat. The recent emphasis on recruitment limitation and supply-side ecology in marine systems has produced a wealth of studies on physical and biological factors affecting larval supply. For temperate reef fishes, as well as many other organisms, we need to integrate these questions regarding larval delivery into a broader framework that includes an increased understanding of the habitat characteristics that cue larval settlement (e.g. Sweatman 1988) and significantly affect subsequent survivorship and growth.

Acknowledgements. Support was provided by National Undersea Research Center/UNCW grants 9209, 9304, 9411 with supplemental support provided by NSF grant OCE 9202847 Assistance in the field was provided by Dan Aspenliter, Robin Bolser, Greg Cronin, Mike Deal, Ken Johns, Greg McFall, Margaret Miller, Glenn Safrit, Jay Stachowicz, Glen Taylor and Kevin Violeta. T Anderson, J. A. Coyer, C. H. Peterson and anonymous reviwers provided critical comments on the manuscript. 


\section{LITERATURE CITED}

Anderson TW (1993) An evaluation of density dependence in a marine temperate reef fish: competitive and predatory effects. PhD dissertation, University of California, Santa Barbara

Anderson TW (1994) Role of macroalgal structure in the distribution and abundance of a temperate reef fish. Mar Ecol Prog Ser 11:279-290

Carpenter RC (1990) Mass mortality of Diadema antillarum I Long-term effects on sea urchin population-dynamics and coral reef algal communities. Mar Biol 104:67-77

Carr MH (1989) Effects of macroalgal assemblages on the recruitment of temperate zone reef fishes. J exp mar Biol Ecol 126:59-76

Carr MH (1991a) Patterns, mechanisms, and consequences of recruitment of a temperate marine reef fish. PhD dissertation, University of California, Santa Barbara

Carr MH (1991b) Habitat selection and recruitment of an assemblage of temperate zone reef fishes. J exp mar Biol Ecol 146:113-137

Carr MH (1994a) Predicting the response of recruitment of temperate reef fishes due to changes in macrophyte density caused by disturbance. In: Stouder DJ, Fresh K (eds) Theory and application in the feeding ecology of fishes. Belle Baruch Marine Institute Series, Univ of South Carolina Press, Columbia

Carr MH (1994b) Effects of macroalgal dynamics on recruitment of a temperate reef fish. Ecology 75:1320-1333

Choat JH, Ayling AM (1987) The relationship between habitat structure and fish faunas on New Zealand Reefs. J exp mar Biol Ecol 110:257-284

Connell SD, Jones GP (1991) The influence of habitat complexity on postrecruitment processes in a temperate reef fish population. J exp mar Biol Ecol 151:271-294

Coyer JA (1979) The invertebrate assemblage associated with Macrocystis pyrifera and its utilization as a food source by kelp forest fishes. PhD dissertation, University of Southern California, Los Angeles

Dayton PK (1973) Dispersion, dispersal and persistence of the annual intertidal alga Postelsia palmaeformis Ruprecht Ecology 54:433-438

DeMartini EE, Roberts DA (1990) Effects of giant kelp (Macrocystis) on the density and abundance of fishes in a cobble-bottom kelp forest. Bull mar Sci 46:287-300

Doherty PJ, Fowler A.J (1994) An empirical test of recruitment limitation in a coral reef fish. Science 263:935-939

Doherty PJ, Williams DMcB (1988) The replenishment of coral reef fish populations. Oceanogr mar Biol A Rev 26 $487-551$

Ebeling AW, Hixon MA (1991) Tropical and temperate reef fishes: comparison of community structures. In: Sale PF (ed) The ecology of fishes on coral reefs. Academic Press, San Diego, CA, p 475-563

Ebeling AW, Laur DR (1985) The influence of plant cover on surfperch abundance at an offshore temperate reef. Environ Biol Fish 12:169-179

Forrester GE (1990) Factors influencing the juvenile demography of a coral reef fish. Ecology 71:1666-1681

Gaines SD, Roughgarden J (1985) Larval settlement rates: a leading determinant of structure in an ecological community of the marine intertidal zone. Proc Natl Acad Sci 82: $3707-371.1$

Grimes CB, Manooch CS, Huntsman GR (1982) Reef and rock outcropping fishes of the outer continental shelf of North Carolina and South Carolina, and ecological notes on the. red porgy and vermilion snapper. Bull mar Sci 31:277-289
Grosberg RK, Levitan DR (1992) For adults only? Supply-side ecology and the history of larval biology. Trends Ecol Evol $7: 130-133$

Harrıs LG, Ebeling AW, Laur DR, Rowley RJ (1984) Community recovery after storm damage: a case of facilitation in primary succession. Science 224:1336-1338

Hay ME, Fenical W (1988) Marine plant-herbivore interactions: the ecology of chemical defense. A Rev Ecol Syst 19: $111-145$

Hixon MA (1980) Competitive interactions between California reef fishes of the genus Embiotoca. Ecology 61: 918-931

Hixon MA, Beets JP (1993) Predation, prey refuges and the structure of coral-reef assemblages Ecol Monogr 63: $77-101$

Holbrook SJ, Carr MH, Schmitt RJ, Coyer JA (1990a) Effect of giant kelp on local abundance of reef fishes: the importance of onlogenetic resource requirements. Bull mar Sci 47:104-114

Holbrook SJ, Schmitt RJ (1984) Experimental analysis of patch selection by foraging black surfperch (Embiotoca jacksoni). J exp mar Biol Ecol 79:39-64

Holbrook SJ. Schmitt RJ (1988) The combined effects of predation risk and food reward on patch selection. Ecology 69:125-134

Holbrook SJ, Schmitt RJ, Ambrose RF (1990b) Biogenic habitat structure and characteristics of temperate reef fish assemblages. Aust J Ecol 15:489-503

Hulburt SH (1971) The nonconcept of species diversity: a critique and alternative parameters. Ecology 52:577-586

Jones GP (1984a) Population ecology of the temperate reef fish Pseudolabrus celidotus Bloch \& Schneider (Pisces: Labridae). I. Factors influencing recruitment. J exp mar Biol Ecol 75:257-276

Jones GP (1984b) Population ecology of the temperate reef fish Pseudolabrus celidotus Bloch \& Schneider (Pisces: Labridae). II. Factors influencing adult density. J exp mar Biol Ecol 75:277-303

Jones GP (1984c) The influence of habitat and behavioural interactions on the local distribution of the wrasse Pseudolabrus celidotus. Environ Biol Fish 10:43-58

Jones GP (1988). Ecology of rocky reef fish of north-eastern New Zealand: a review. NZ J mar Freshwat Res 22: $445-462$

Jones GP (1991) Postrecruitment processes in the ecology of coral reef fish populations: a multifactorial perspective. In: Sale PF (ed) The ecology of fishes on coral reefs. Academic Press, San Diego, CA, p 1691-1698

Larson RJ (1980) Competition, habitat selection and the bathymetric segregation of two rockfish (Sebastes) species. Ecol Monogr 50:221-239

Levin PS (1991) Effects of microhabitat on recruitment variation in a Gulf of Maine reef fish. Mar Ecol Prog Ser 75 $183-189$

Levin PS (1993) Habitat structure, conspecific presence and spatial variation in the recruitment of a temperate reef fish. Oecologia 94:176-185

Levin PS (1994a) Small-scale recruitment variation in a temperate fish: the roles of macrophytes and food supply. Environ Biol Fish 40:271-281

Levin PS (1994b) Fine-scale recruitment variation in a temperate demersal fish: the importance of settlement versus post-settlement processes. Oecologia 97:124-133

McAuliffe JR (1986) Herbivore-limited establishment of Sonoran Desert tree, Cercidium microphyllum. Ecology 67 $276-280$

Menge BA, Sutherland JP (1987) Community regulation: vari- 
ation in disturbance, competition and predation in relation to environmental stress and recruitment. Am Nat 130:730-757

Ólafsson EB, Peterson CH, Ambrose WG (1994) Does recruitment limitation structure populations and communities of macroinvertebrates in marine soft sediments: the relative significance of pre- and post-settlement processes. Oceanogr mar Biol A Rev 32:65-109

Orth RJ, Heck KL, van Montfrans J (1984) Faunal communities in seagrass beds: a review of the influence of plant structure and prey characteristics on predator-prey relationships. Estuaries 7:339-350

Paine RT (1979) Disaster, catastrophe and local persistence of the sea palm Postelsia palmaeformis. Science 205:685-687

Parker RO, Colby DR, Willis TD (1983) Estimated amount of reef habitat on a portion of the US Atlantic and Gulf of Mexico continental shelf. Bull mar Sci 33:935-940

Roughgarden J, Gaines S, Possingham H (1988) Recruitment dynamics in complex life cycles. Science 241:1460-1466

Sale PF (1980) The ecology of fishes on coral reefs. Oceanogr mar Biol A Rev 18:367-421

Sale PF (1991) The assembly of reef fish communities: open non-equilibrial systems. In: Sale PF (ed) The ecology of fishes on coral reefs. Academic Press, San Diego, CA, p $564-598$

Sale PF, Douglas WA (1981) Precision and accuracy of visual census technique for fish assemblages on coral patch reefs. Environ Biol Fish 6:333-339

This article was presented by C. H. Peterson (Senior Editorial Advisor), Morehead City, North Carolina, USA
Schmitt RS, Holbrook SJ (1990) Contrasting effects of giant kelp on dynamics of surfperch populations. Oecologia 84 $419-429$

Sedberry GR, Van Dolah RF (1984) Demersal fish assemblages associated with hard bottom habitat in the South Atlantic Bight of the USA. Environ Biol Fish 11:241-258

Shulman MJ, Ogden JC (1987) What controls tropical reef fish populations: recruitment or benthic mortality? An example in the Caribbean reef fish Haemulon flavolineatum. Mar Ecol Prog Ser 39:233-242

Sogard SM (1989) Colonization of artifical seagrass by fishes and decapod crustaceans: importance of proximity to natural eelgrass. J exp mar Biol Ecol 133:15-37

Sweatman HPA (1988) Field evidence that settling coral reef fish larvae detect resident fishes using dissolved chemical cues. J exp mar Biol Ecol 124:163-174

Underwood AJ, Denley EJ (1984) Paradigms, explanations and generalizations in models for the structure of intertidal communities of rocky shores. In: Strong DR, Simberloff D. Abele LG, Thistle AB (eds) Ecological communities: conceptual issues and the evidence. Princeton Univ Press, Princeton, NJ, p 151-180

Underwood AJ, Fairweather PG (1989) Supply-side ecology and benthic assemblages. Trends Ecol Evol 4:16-19

Werner EE, Gilliam JF (1984) The ontogenetic niche and species interactions in size-structured populations. A Rev Ecol Syst 15:393-425

Manuscript first received: June 6, 1995

Revised version accepted: August 15, 1995 